\title{
The density of negative charge in the cell wall influences two-component signal transduction in Bacillus subtilis
}

Correspondence

Vesa P. Kontinen

Vesa.Kontinen@ktl.fi

Received 30 August 2006

Revised 2 April 2007

Accepted 5 April 2007

\author{
Hanne-Leena Hyyryläinen, ${ }^{1}$ Milla Pietiäinen, ${ }^{1}$ Tuula Lundén, ${ }^{1}$ \\ Anna Ekman, ${ }^{1}$ Marika Gardemeister, ${ }^{1}$ Sanna Murtomäki-Repo, ${ }^{1}$ \\ Haike Antelmann, ${ }^{2}$ Michael Hecker, ${ }^{2}$ Leena Valmu, ${ }^{3}+$ Matti Sarvas ${ }^{1}$ \\ and Vesa P. Kontinen ${ }^{1}$
${ }^{1}$ Vaccine Development Laboratory, Department of Vaccine, National Public Health Institute, Mannerheimintie 166, FIN-00300 Helsinki, Finland
${ }^{2}$ Institut für Mikrobiologie und Molecularbiologie, Ernst-Moritz-Arndt-Universität Greifswald, F.-L.-Jahn-str. 15, D-17487 Greifswald, Germany
${ }^{3}$ Institute of Biotechnology, University of Helsinki, Viikki Biocenter, PO Box 56, FIN-00014, University of Helsinki, Finland

\begin{abstract}
The Dlt system modulates the density of negative charge in the cell wall of Gram-positive bacteria by substituting anionic polymers (wall and lipoteichoic acids) with D-alanine. The $h t r A$ and $h t r B$ genes, regulated by the CssRS two-component system (TCS) and encoding membrane-associated protein quality control proteases, were expressed at strongly decreased levels in a mutant with defective Dlt (dltD:: miniTn10) as compared to the $d l t^{+}$wild-type strain under a secretion stress condition (hypersecretion of Amy $\alpha$-amylase). The level of HtrA protein in the extracellular proteome of the $d l t D$ mutant was decreased consistently. Expression from the promoter of the lialHGFSR (yvqIHGFEC) operon $\left(\mathrm{P}_{\text {lial }}\right)$ is dependent on the LiaRS TCS. The Dlt defect increased the expression from $\mathrm{P}_{\text {lial }}$ under two stress conditions, Amy $\mathrm{Q}$ hypersecretion and treatment with a cationic antimicrobial peptide (LL-37), but decreased the expression in vancomycin-treated cells. Furthermore, Dlt inactivation enhanced the expression of the YxdJK-regulated $y x d L$ gene in LL-37-treated cells. The increased net negative charge of the cell wall seems to cause varied and opposite effects on the expression of CssRS-, LiaRS- and YxdJK-regulated genes under different stress conditions. The results suggest that TCSs which sense misfolded proteins or peptides are modulated by the density of negative charge in the cell wall. The density of negative charge on the outer surface of the cell membrane did not have a similar effect on TCSs.
\end{abstract}

\section{INTRODUCTION}

Two-component signal transduction is involved in controlling the quality of exported proteins in bacteria (Raivio \& Silhavy, 1999; Sarvas et al., 2004). In Bacillus subtilis, the CssRS two-component system (TCS), the B. subtilis functional orthologue of the Escherichia coli CpxRA TCS (Connolly et al., 1997; Danese \& Silhavy, 1997; Missiakas \& Raina, 1997; Pogliano et al., 1997), responds to the accumulation of misfolded proteins at the membrane-cell wall interface (Hyyryläinen et al., 2001; Darmon et al.,

tPresent Address: Finnish Red Cross Blood Service, Research and Development, Kivihaantie 7, FIN-00310, Helsinki, Finland.

Abbreviations: CAMP, cationic antimicrobial peptide; QRT-PCR, quantitative real-time RT-PCR; TCS, two-component system.
2002). CssRS-mediated signalling induces the htrA and $h t r B$ genes, which encode serine-type surface proteases involved in quality control. The expression of these qualitycontrol proteases is strictly dependent on CssRS (Hyyryläinen et al., 2001; Darmon et al., 2002). Severe secretion stress and consequent accumulation of misfolded proteins at the membrane-cell wall interface also induces several other genes in B. subtilis (Hyyryläinen et al., 2005), including the liaIHGFSR operon, the expression of which is also induced by several other stress conditions such as alkaline shock, detergents and cationic antimicrobial peptides (Wiegert et al., 2001; Mascher et al., 2003; Pietiäinen et al., 2005). The last two genes of the lia operon encode a TCS, LiaRS, which regulates expression from the $\mathrm{P}_{\text {liaI }}$ promoter in front of the liaI gene (Mascher et al., 2004). The liaF gene encodes a membrane-bound 
negative regulator of the LiaRS TCS (Jordan et al., 2006). LiaH is similar to E. coli phage shock protein A (PspA). It negatively modulates (weakly) the activity of LiaRdependent promoters (Jordan et al., 2006), whereas the functional roles of LiaI and LiaG are less well known. In addition to $\mathrm{P}_{\text {liaI }}$, there is a weak promoter in the immediate upstream region of liaG, $\mathrm{P}_{\text {liaG }}$, from which the liaGFSR genes are expressed in unstressed cells (Jordan et al., 2006).

PrsA3 is a mutant variant of the PrsA lipoprotein of $B$. subtilis, a membrane-bound peptidyl-prolyl cis/trans-isomerase (Hyyryläinen et al., 2000; Kontinen et al., 1991). We have shown previously that PrsA3 is highly sensitive to cell-associated proteolytic degradation and consequently its cellular level is decreased to only about $10 \%$ of the wildtype level (Hyyryläinen et al., 2000). We have observed that PrsA3 was stabilized at the membrane-cell wall interface in a similar manner in both $\operatorname{css} S$ and $d l t D$ mutants (Hyyryläinen et al., 2000, 2001). Mutations in dlt increase the density of negative charge in the cell wall matrix. In addition to PrsA3, some other mutant and heterologous proteins are also stabilized and their secretion improved when Dlt is inactivated (Craynest et al., 2003; Hyyryläinen et al., 2000; Thwaite et al., 2002; Vitikainen et al., 2005).

Four of the five proteins encoded by the dlt operon (DltA, B, C and D) comprise the Dlt system (Perego et al., 1995). Dlt modifies both lipoteichoic and wall teichoic acids with D-alanine and thereby decreases the density of negative charge in the cell wall. The dlt operon is under the transcriptional control of $\sigma^{\mathrm{X}}$, a sigma factor with an extracytoplasmic function, which belongs to the Bacillus cell envelope stress response network (Cao \& Helmann, 2004) The improved stability of PrsA 3 and other abnormal proteins in dlt mutants raises the question of whether the altered charge of the wall affects post-translocational folding of these proteins and thereby stabilizes them, as suggested previously (Hyyryläinen et al., 2000). Alternatively, Dlt could modulate the quality control of exported proteins. The increased net negative charge of the wall in $d l t$ mutants may increase the binding of divalent cations to the wall and the bound cations may improve posttranslocational folding of exported proteins (Hyyryläinen et al., 2000). Alternatively, the inactivation of Dlt could 'desensitize' the CssRS TCS to misfolded proteins, decrease CssRS-mediated signal transduction, and consequently decrease the expression of the HtrA and HtrB quality control proteases. Indeed, we could demonstrate in this study that in the absence of Dlt, htrA and $h t r B$ were expressed at significantly lower levels than in its presence. It was found that Dlt modulates TCS activity in a manner that is dependent on TCS and the type of inducer/stress.

\section{METHODS}

Bacterial strains, plasmids and growth conditions. The bacterial strains and plasmids used are listed in Table 1 . Bacteria were grown in either Luria-Bertani broth (LB; $1 \%$ tryptone, $0.5 \%$ yeast extract, $1 \%$ $\mathrm{NaCl})$ or modified $2 \times \mathrm{LB}$ broth $\left(2 \times \mathrm{LB}_{5} ; 2 \%\right.$ tryptone, $1 \%$ yeast extract, $1 \% \mathrm{NaCl}$ ) supplemented with appropriate antibiotics, unless otherwise indicated. The final concentrations of the antibiotics were $10 \mu \mathrm{g}$ kanamycin $\mathrm{ml}^{-1}, 5 \mu \mathrm{g}$ chloramphenicol $\mathrm{ml}^{-1}$ and $1 \mu \mathrm{g}$ erythromycin $\mathrm{ml}^{-1}$. For gene expression measurements, bacteria were grown in the absence of antibiotics to avoid putative antibiotic effects on gene expression. Expression from the $\mathrm{P}_{\text {spac }}$ and $\mathrm{P}_{x y n}$ promoters was induced by adding $1 \mathrm{mM}$ IPTG and $0.2 \%$ xylose, respectively, to the growth medium.

Two plasmids, pKTH10 and pKTH3339, were used to cause secretion stress. The pKTH10 plasmid is a derivative of pUB110 with an insert containing the amyQ gene of Bacillus amyloliquefaciens (Palva et al., 1982). In pKTH3339 (a derivative of pSX50; Hastrup \& Jacobs, 1990), amyQ has been placed under $\mathrm{P}_{x y n}$ control (Vitikainen et al., 2001). Strains harbouring these plasmids secrete AmyQ at high levels into the extracellular medium. The LL-37 antimicrobial peptide (purchased from Dr Ale Närvänen, University of Kuopio, Finland, or from EzBiolab) and vancomycin were added in the early exponential growth phase $\left(\sim 60\right.$ Klett units, $\left.\mathrm{OD}_{560}=0.6\right)$ to cause cell envelope stress, and were used at the subinhibitory concentrations of 4 or $6 \mu \mathrm{g}$ $\mathrm{ml}^{-1}$ and $2 \mu \mathrm{g} \mathrm{ml}{ }^{-1}$, respectively. Triton X-100 was added at the density of 100 Klett units (to cause stress) and used at a concentration of $0.005 \%$.

Transcription analysis by quantitative real-time RT-PCR (QRTPCR). Total cellular RNA was isolated for QRT-PCR as described previously (Pietiäinen et al., 2005) or as follows. RNA was extracted by using the Roche High Pure RNA isolation kit according to the manufacturer's instructions. Bacteria from $2 \mathrm{ml}$ of an exponentialphase culture were resuspended in lysis buffer $(10 \mathrm{mM}$ Tris- $\mathrm{HCl}$, $1 \mathrm{mM}$ EDTA, pH 7.0, $1 \mathrm{mg}$ lysozyme $\mathrm{ml}^{-1}$ ) and incubated at $37{ }^{\circ} \mathrm{C}$ for $10 \mathrm{~min}$. The subsequent steps were performed as described by the kit manufacturer. If cells were treated with LL-37, vancomycin or Triton X-100 to cause stress, the treatments were continued for 10 or $20 \mathrm{~min}$, followed by harvesting of the cells and extraction of the RNA. Secretion stress was caused by overexpressing the $\alpha$-amylase of $B$. amyloliquefaciens (AmyQ) from the pKTH3339 plasmid (Hyyryläinen et al., 2001). $\mathrm{P}_{x y n^{-}}$amyQ in pKTH3339 was induced with $0.2 \%$ xylose at the density of 60 Klett units for $30 \mathrm{~min}$, followed by RNA extraction. cDNA synthesis was carried out by using the high capacity cDNA archive kit (Applied Biosystems) with an additional step of DNase I treatment. Each reaction mixture consisted of $5 \mu \mathrm{l}$ $10 \times$ buffer, $2 \mu \mathrm{l} 25 \mathrm{mM}$ dNTP, $5 \mu \mathrm{l}$ hexamer, $11 \mu \mathrm{l} 25 \mathrm{mM} \mathrm{MgCl}_{2}$, $5 \mu \mathrm{l} 20 \mathrm{U}$ DNase (Roche) and $1 \mu \mathrm{g}$ RNA in $50 \mu$ total volume. The mixture was divided into two equal portions and $1.3 \mu$ l reverse transcriptase (MultiScribe) was added to one. The cDNA synthesis reaction was carried out in a thermal cycler with the following steps: (i) DNase I treatment at $37^{\circ} \mathrm{C}$ for $30 \mathrm{~min}$, (ii) inactivation of DNase I by incubating at $75{ }^{\circ} \mathrm{C}$ for $5 \mathrm{~min}$, (iii) cooling to $4{ }^{\circ} \mathrm{C}$, (iv) addition of reverse transcriptase, (v) cDNA synthesis at $25^{\circ} \mathrm{C}$ for $10 \mathrm{~min}$, and (vi) at $37{ }^{\circ} \mathrm{C}$ for $120 \mathrm{~min}$. QRT-PCR was carried out as described previously (Pietiäinen et al., 2005) using the SYBR Green PCR master mix (Applied Biosystems) and a 7500 real-time PCR system (Applied Biosystems). The cDNA values were normalized with the value of gyrA (Pietiäinen et al., 2005). Sequences of the QRT-PCR primers for the genes studied are shown in Table 2.

PMUTIN constructions and $\boldsymbol{\beta}$-galactosidase assay. The pMUTIN2 (Vagner et al., 1998) inserts in the liaI and mprF (yfiW and $y f i X)$ genes constructed in the Bacillus subtilis Functional Analysis (BSFA) program (Kobayashi et al., 2003) were used to study expression of these genes. Due to a sequencing error (an extra cytidine nucleotide) at position 916935 of the B. subtilis genome sequence, the $m p r F$ gene has been misidentified as two different genes, $y f i W$ and $y f i X$ (Staubitz \& Peschel, 2002). The pMUTIN2 insertion sites in the $y f i W:: p M U T I N 2$ and $y f i X::$ pMUTIN2 mutants are located at 248 and 977 ( 1 is the first nucleotide of the initiation 
Table 1. Bacterial strains and plasmids

\begin{tabular}{|c|c|c|}
\hline $\begin{array}{l}\text { Strain or } \\
\text { plasmid }\end{array}$ & Relevant genotype and characteristics & Reference \\
\hline \multicolumn{3}{|l|}{ Strains } \\
\hline IH6531 & $\operatorname{trpC2}$ glyB133 hisA1 pKTH10 & Leskelä et al. (1999) \\
\hline IH6538 & $\operatorname{trpC2}$ glyB133 hisA1 & Leskelä et al. (1999) \\
\hline IH7144 & prsA3 glyB133 hisA1 pKTH10 & Hyyryläinen et al. (2000) \\
\hline IH7171 & prsA3 glyB133 hisA1 & Hyyryläinen et al. (2001) \\
\hline IH7375 & dltD:: miniTn $10 \operatorname{trpC}$ glyB133 hisA1 & Vitikainen et al. (2005) \\
\hline IH7378 & dltD:: miniTn 10 trpC2 glyB133 hisA1 pKTH10 & This study \\
\hline IH7558 & prsA3 glyB133 hisA1 pKTH3339 & Hyyryläinen et al. (2001) \\
\hline IH7612 & htrA::pMUTIN2 trpC2 glyB133 hisA1 pKTH10 & This study \\
\hline IH7663 & yhcT:: pMUTIN2 prsA3 glyB133 hisA1 pKTH3339 & Hyyryläinen et al. (2001) \\
\hline IH7988 & htrB::pMUTIN4 trpC2 glyB133 hisA1 pKTH10 & This study \\
\hline IH8112 & liaR::pMUTIN2 prsA3 glyB133 hisA1 pKTH3339 & This study \\
\hline $\mathrm{IH} 8122^{*}$ & trpC2 hisA1 glyB133 pKTH10; parental strain & Leskelä et al. (1999) \\
\hline IH $8123^{*}$ & $\operatorname{trpC2}$ hisA1 glyB133; parental strain & Leskelä et al. (1999) \\
\hline IH8149 & htrA::pMUTIN2 dltD:: miniTn10 trpC2 glyB133 hisA1 pKTH10 & This study \\
\hline IH8205 & liaI:: pMUTIN2 dltD:: miniTn10 trpC2 glyB133 hisA1 pKTH10 & This study \\
\hline IH8207 & liaI::pMUTIN2 trpC2 glyB133 hisA1 pKTH10 & This study \\
\hline IH8219 & liaI: : pMUTIN2 trpC2 glyB133 hisA1 & This study \\
\hline IH8220 & liaI::pMUTIN2 dltD:: miniTn10 trpC2 glyB133 hisA1 & This study \\
\hline IH8268 & htrB::pMUTIN4 dltD:: miniTn10 trpC2 glyB133 hisA1 pKTH10 & This study \\
\hline IH8394 & $\operatorname{mprF}(y f i X)::$ pMUTIN2 trpC2 glyB133 hisA1 & This study \\
\hline IH8396 & $m p r F(y f i X)::$ pMUTIN2 trpC2 glyB133 hisA1 pKTH10 & This study \\
\hline IH8429 & psd1:: neo trpC2 glyB133 hisA1 & This study \\
\hline IH8430 & $m p r F(y f i W)::$ pMUTIN2 trpC2 glyB133 hisA1 & This study \\
\hline IH8434 & psd1:: neo prsA3 glyB133 hisA1 pKTH3339 & This study \\
\hline \multicolumn{3}{|l|}{ Plasmids } \\
\hline pKTH10 & $\mathrm{P}_{a m y Q^{-}} a m y \mathrm{Q} ; \mathrm{Km}^{\mathrm{r}}$ & Palva et al. (1982) \\
\hline pKTH3339 & $\mathrm{P}_{x y n}-a m y Q ; \mathrm{Cm}^{\mathrm{r}}$ & Vitikainen et al. (2001) \\
\hline
\end{tabular}

${ }^{*}$ IH8122 and IH8123 are reisolations of IH6531 and IH6538, respectively (Leskelä et al. 1999).

codon) in the $2568 \mathrm{nt} m p r F$ gene, respectively. The $h t r A::$ pMUTIN2 and htrB::pMUTIN4 constructs used in this study have been described previously (Hyyryläinen et al., 2001; Darmon et al., 2002). $\beta$-Galactosidase activity was determined with ONPG (Merck) substrate as described previously (Msadek et al., 1990) and the activity was expressed in Miller units per milligram total protein.

2D gel electrophoresis analysis. To prepare extracellular protein extracts, B. subtilis strains were grown at $37{ }^{\circ} \mathrm{C}$ under vigorous agitation in LB medium. After $1 \mathrm{~h}$ of post-exponential growth, cells were separated from the growth medium by centrifugation. The secreted proteins in the growth medium were precipitated with $10 \%$ TCA and prepared for 2D PAGE, as described previously (Antelmann et al., 2001). IEF was performed as described previously (Buttner $e t$ al., 2001) using commercially available IPG Strips (Amersham Biosciences) in the $\mathrm{pH}$ range $3-10$ for extracellular proteins. Separation in the second dimension was performed using $12 \%$ polyacrylamide gels. Analytical gels were loaded with $200 \mu \mathrm{g}$ protein. Gels were stained with either silver nitrate (O’Connell \& Stults, 1997) or SYPRO Ruby protein gel stain (Molecular Probes) according to the

Table 2. Specific primer pairs for QRT-PCR

\begin{tabular}{|c|c|c|}
\hline Gene & Forward primer & Reverse primer \\
\hline gyrA & 5'-GATTATTAACCTGCTGGAGGTAGAAAA-3' & 5'-AGGTAAAGCTCCGCATTGAATTC-3' \\
\hline liaI $(y v q I)$ & 5'-CATCTGCTCACTTCCGTTTGTC-3' & 5'-TTCCAGCCGTAATACACCATAGC-3' \\
\hline $\operatorname{liaH}(y v q H)$ & 5'-TCCAAAGGTGATGCTGAATCAA-3' & 5'-GTTTCACAATTGTTTGCTTTGCTT-3' \\
\hline $\operatorname{lia} G(y v q G)$ & 5'-GCCGGGAATGACCATCTTG-3' & 5'-CGTCCGTCACGCTCGTATTT-3' \\
\hline $\operatorname{liaF}(y v q F)$ & 5'-CCGACATGCGCAGCTTTT-3' & 5'-TCAGGTCAAACGGCTGCTT-3' \\
\hline $\operatorname{liaS}(y v q E)$ & 5'-GATCAGGATGGTCGAGCATATG-3' & 5'-GCAGCGCCCTCATCTCATT-3' \\
\hline $\operatorname{liaR}(y v q C)$ & 5'-CGCGCCGCAAGCAA-3' & 5'-CGCAGCCTGGATAATACTTTTCC-3' \\
\hline$y x d L$ & 5'-GGTCATTCATAAGCCGTCACTCA-3' & 5'-TTGTCGCTTTGGAATCAAGGT-3' \\
\hline
\end{tabular}


manufacturer's instructions. Proteins were identified using MALDITOF MS, as described previously (Antelmann et al., 2002). Quantitative image analysis was performed by using the false-colour image analysis and quantification tool of the DECODON Delta 2D software (http://www.decodon.com).

\section{RESULTS}

\section{Induction of htrA and $h$ trB by secretion stress is abolished in the absence of $D$-alanylated teichoic acids}

In order to find out whether the increased net negative charge of the cell wall in dlt mutants causes downregulation of expression of the $h \operatorname{tr} A$ and $h \operatorname{tr} B$ genes and thereby stabilization of the PrsA3 protein, a lacZ reporter was placed under the control of the protease gene promoters and $\beta$-galactosidase activity was measured. The lac $Z$ reporter was placed under the transcriptional control of the htrA and $h \operatorname{tr} B$ genes by inserting pMUTIN plasmids (Vagner et al., 1998) into the protease genes. The strains expressed AmyQ $\alpha$-amylase from the pKTH10 plasmid and secreted it at a high level (hypersecretion). This caused secretion stress, activated signal transduction via the CssRS TCS and induced the CssRS-regulated $\mathrm{P}_{h t r A}$ and $\mathrm{P}_{h t r B}$ promoters (Hyyryläinen et al., 2001).

In the wild-type strain, AmyQ hypersecretion resulted in about 10-fold induction of $\mathrm{P}_{\text {htrA }}$ expression (Fig. 1a), consistent with previously published results (Hyyryläinen et al., 2001). Secretion stress caused a similar induction of expression from the $\mathrm{P}_{h t r B}$ promoter (Fig. 1b). In contrast, hardly any induction of $\mathrm{P}_{h t r A}$ and $\mathrm{P}_{h t r B}$ was observed in the $d l t D$ mutant (Fig. 1a, b; representative results of two experiments are shown in each panel). These results suggest that the D-alanylation of teichoic acids modulates signal transduction via CssRS.

Extracellular proteomes of the dltD mutant and the wildtype strain were compared using $2 \mathrm{D}$ gel electrophoresis. False-colour images of the proteomes (Fig. 2; representative results of two experiments are shown) revealed that the majority of the protein spots were yellow, suggesting that most extracellular proteins were secreted at similar levels from the two strains. A significant fraction of the proteins in the extracellular proteome were cytoplasmic proteins, probably released into the culture medium by cell lysis (Tjalsma et al., 2004). The cytoplasmic proteins included $\mathrm{CitH}$, Eno, SodA and PdhD. The false-colour images of the spots for these proteins suggested that the two strains were not significantly different in their degree of cell lysis (Fig. 2).

The normally cell membrane/wall-associated HtrA protease is also present in the extracellular proteome in abundant amounts (Tjalsma et al., 2004). A prominent finding in this study was that HtrA accumulated at a significantly lower level in the culture medium of the dltD mutant than in that of the wild-type strain (Fig. 2). This is in good agreement (a)

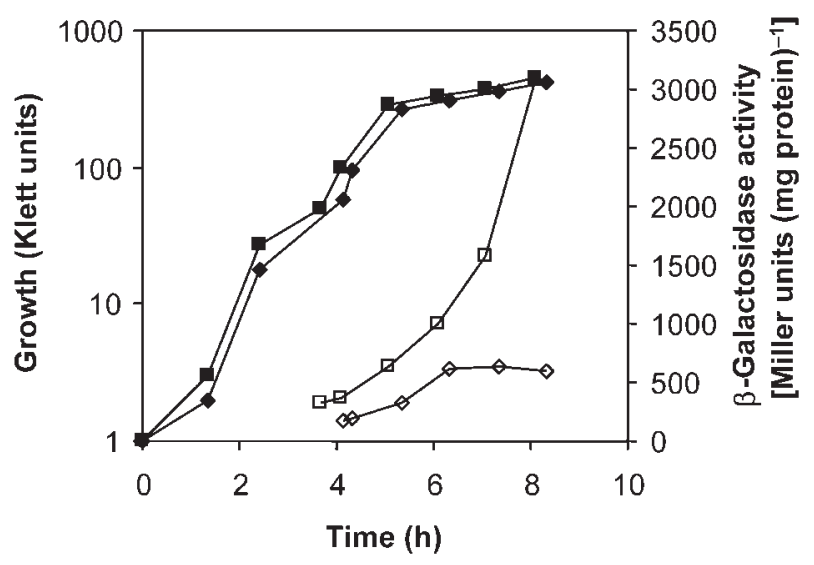

(b)

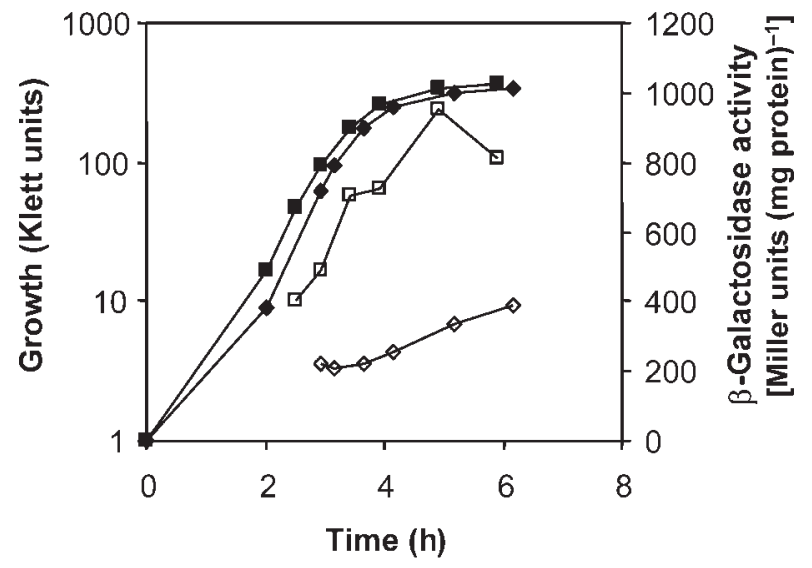

Fig. 1. The effect of $d l t D::$ miniTn 10 on the expression of $h t r A$ and htrB. (a) Strains IH8149 (dltD::miniTn10 htrA::pMUTIN2 pKTH10) and IH7612 (dlt ${ }^{+}$htrA::pMUTIN2 pKTH10) were cultivated in $2 \times \mathrm{LB}_{5}$, and $\beta$-galactosidase activities of cell samples taken at the indicated time points during growth were determined. The strains secreted Amy $\alpha$-amylase at high levels due to the presence of the pKTH10 plasmid. Squares, $d / t^{+}$; diamonds, $d l t D$ : : miniTn 10; filled symbols, growth; open symbols, $\beta$-galactosidase activity. (b) Experiment performed with strains $\mathrm{IH} 7988\left(d / t^{+}\right.$ htrB::pMUTIN4 pKTH10) and IH8268 (dltD::miniTn10 htrB: : pMUTIN4 pKTH10) as in (a).

with the decreased transcription of the htrA gene in the $d l t D$ mutant. Consistent with the decreased amount of $\mathrm{HtrA}$ in the proteome of the dltD mutant, we also detected decreased secretion of YqxI, which is probably stabilized post-transcriptionally by the chaperone-like activity of HtrA in response to secretion stress (Antelmann et al., 2003). The extracellular proteome analysis further suggested that some other proteins were also present at decreased levels in the culture medium of the dltD mutant, including the $\mathrm{PbpX}$ penicillin-binding protein, and $\mathrm{YrpD}$ and $\mathrm{YxkC}$, whose functions are unknown. 

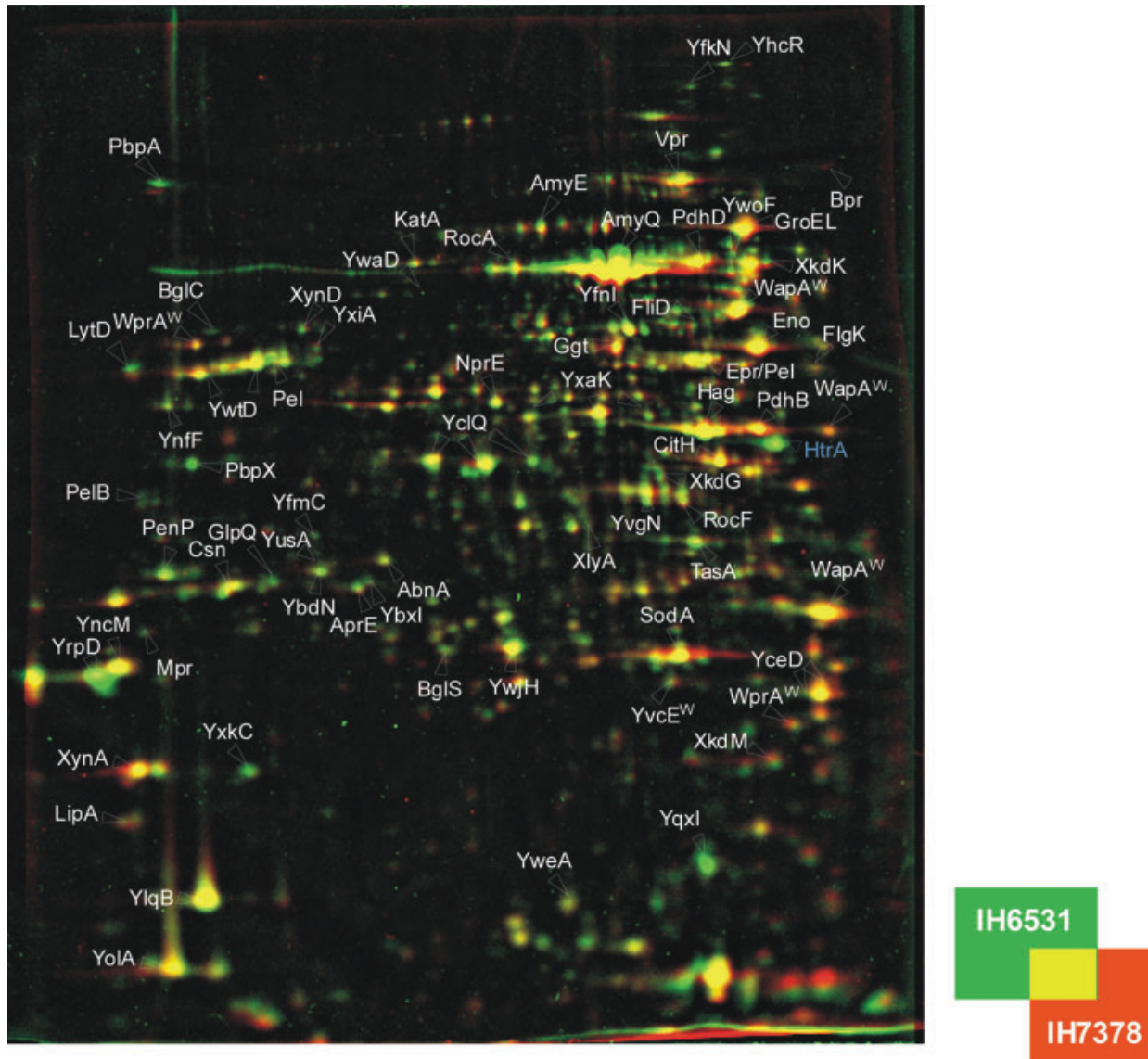

Fig. 2. Comparison of extracellular proteomes of the $d l t D::$ miniTn 10 mutant and its wild-type $\left(d / t^{+}\right)$parent. Superimposed false-colour images of extracellular proteomes of IH6531 (dlt ${ }^{+}$pKTH10) and IH7378 (dltD:: miniTn10 pKTH10) are shown. Extracellular proteins were TCA-precipitated from the culture medium of late-exponential-phase cultures and separated by 2D gel electrophoresis. The colour code of the spots indicates the relative abundance of the proteins in the extracellular proteomes of the two strains. The spot for HtrA protease is indicated by blue type.

\section{Induction of expression from the LiaRS-regulated $P_{\text {lial }}$ promoter in secretion stress and stress caused by cationic antimicrobial peptides is dependent on the cell wall charge}

The liaIHGFSR gene cluster is strongly induced in an unspecific manner by antibiotics that interfere with the lipid II cycle, membrane-active cationic antimicrobial peptides (CAMPs) such as LL-37, detergents such as Triton X-100 (Mascher et al., 2004; Pietiäinen et al., 2005) and severe secretion stress (AmyQ secretion at a high level and a defect in the PrsA petidyl-prolyl cis/trans isomerase; Hyyryläinen et al., 2005). Expression from the liaI promoter $\left(\mathrm{P}_{\text {liaI }}\right)$ is strictly dependent on the LiaRS TCS, encoded by the liaR and liaS genes in the same gene cluster (Mascher et al., 2003). Severe secretion stress (amyQ expressed from pKTH3339 and impaired post-translocational folding due to the prsA3 mutation) caused no induction of liaI expression in a knockout mutant of liaR, whereas a 77-fold induction (QRT-PCR measurement) was seen in the wild-type. A similar result was obtained with
LL-37: liaI was induced 55-fold in wild-type cells and not at all in liaR mutant cells. These results are similar to the LiaRS-dependent induction of liaIH in cells treated with bacitracin (Mascher et al., 2003).

In order to find out whether the Dlt system, and consequently the density of negative charge in the cell wall, modulates stress responses mediated by two-component sensory systems other than CssRS, the effect of dltD::miniTn 10 on the expression from the LiaRSregulated $\mathrm{P}_{\text {liaI }}$ promoter was determined. The pMUTIN2 plasmid (Vagner et al., 1998) was inserted into the liaI gene. The plasmid insert probably inactivated liaI, placed a lacZ reporter under the control of $\mathrm{P}_{\text {liaI }}$ and placed the downstream genes of the lia operon under the control of the IPTG-inducible $\mathrm{P}_{\text {spac }}$ promoter. The $\mathrm{P}_{\text {liaI }}$ promoter was induced by either subjecting the cells to AmyQ hypersecretion or treating them with LL-37.

The effect of the $\mathrm{P}_{\text {spac }}$ induction on the expression of the downstream genes, liaHGFSR, was determined in the 
absence and presence of IPTG by using QRT-PCR. In the absence of IPTG, they were expressed at low levels (Table 3). However, the expression levels of liaGFSR were clearly higher than that of liaH ( $>10$-fold higher levels of cDNA), consistent with the presence of the weak $\mathrm{P}_{\text {liaG }}$ promoter in the upstream region of liaG (Jordan et al., 2006). When $P_{\text {spac }}$ was induced with $1 \mathrm{mM}$ IPTG, all five downstream genes were strongly induced. In the case of $\mathrm{liaH}$, the induction was about 500 -fold as compared to the level in the absence of IPTG. The expression levels were similar in the $d t^{+}$(wild-type) strain (IH8207) and the $d l t D::$ miniTn 10 mutant (IH8205).

$\mathrm{P}_{\text {liaI }}$ expression was first determined in the absence of IPTG (the $\mathrm{P}_{\text {spac }}$-liaHGFSR genes expressed at low levels) by measuring $\beta$-galactosidase activity. In wild-type cells secreting AmyQ, $\mathrm{P}_{\text {liaI }}$ was induced only slightly (Fig. 3a). This is consistent with our previous DNA macroarray results (Hyyryläinen et al., 2005) showing that the lia operon is not significantly induced by mere AmyQ hypersecretion, but it is induced if there is also a mutation in the gene encoding the post-translocational folding factor PrsA. In the present study, about fivefold higher $\mathrm{P}_{\text {liaI }}$ expression levels (LacZ measurement) were observed in the dltD::miniTn 10 mutant than in the wild-type strain (Fig. 3a). In the presence of IPTG and thus the downstream $\mathrm{P}_{\text {spac }}$-liaHGFSR genes expressed at higher levels than in its absence, the results were distinctly different. In the wildtype strain, the overall $\mathrm{P}_{\text {liaI }}$ expression levels were similar to those in the absence of IPTG (Fig. 3a, b). However, the dltD: : miniTn 10 mutation conferred no expression-enhancing effect on $\mathrm{P}_{\text {liaI }}$ (Fig. 3b).

When cells were treated with LL-37, the expression from $\mathrm{P}_{\text {liaI }}$ was clearly upregulated (up to $\sim 10$-fold) in the dltD:: miniTn 10 mutant under both conditions (with or without IPTG; Fig. 4a, b). The $\mathrm{P}_{\text {lial }}$ expression returned to the low initial level in about $4 \mathrm{~h}$ from the addition of

Table 3. Expression levels of the lia genes downstream of the lial: : pMUTIN2 insertion site and under the control of the $P_{\text {spac }}$ promoter

\begin{tabular}{|c|c|c|c|c|}
\hline \multirow[t]{3}{*}{ Gene } & \multicolumn{4}{|c|}{ Expression levels of $\mathrm{P}_{\text {spac }}$-liaHGFSR ${ }^{\star}$} \\
\hline & \multicolumn{2}{|c|}{$d l t^{+}$} & \multicolumn{2}{|c|}{ dltD: : miniTn 10} \\
\hline & -IPTG & + IPTG & -IPTG & + IPTG \\
\hline liaH & 0.002 & 1.065 & 0.004 & 2.396 \\
\hline $\operatorname{lia} G$ & 0.081 & 3.008 & 0.155 & 2.082 \\
\hline liaF & 0.038 & 0.526 & 0.041 & 0.294 \\
\hline lias & 0.173 & 2.014 & 0.305 & 1.758 \\
\hline liaR & 0.131 & 1.055 & 0.190 & 0.784 \\
\hline
\end{tabular}

${ }^{*}$ Strains (IH8205 and IH8207) were grown in either the absence or the presence of IPTG to a cell density of 60 Klett units, and $\mathrm{P}_{\text {spac }}$ liaHGFSR gene expression levels were determined by QRT-PCR. Values are ng DNA. (a)

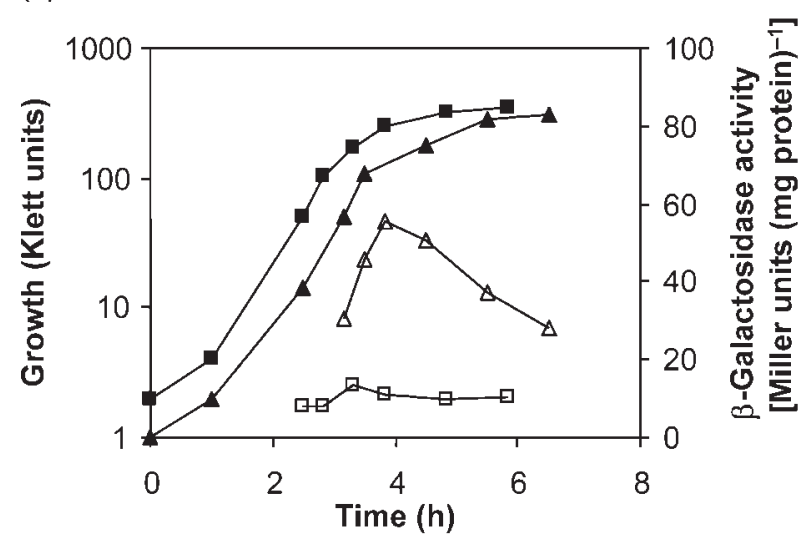

(b)

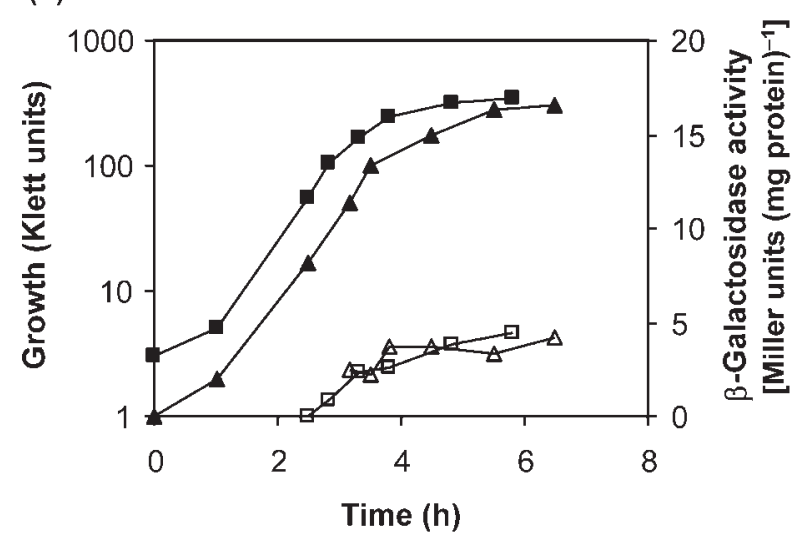

Fig. 3. Induction of $\mathrm{P}_{\text {lial }}$ in the $d / t D::$ miniTn 10 mutant by secretion stress. (a) Strains IH8205 (dltD:: miniTn10 lial:: pMUTIN2 pKTH10) and IH8207 (dlt ${ }^{+}$lial::pMUTIN2 pKTH10) secreting Amy $\alpha$-amylase at high levels were cultivated in $2 \times \mathrm{LB}_{5}$, and $\beta$ galactosidase activities of cell samples taken at the indicated time points during growth were determined. The lia genes downstream of lial $\left(\mathrm{P}_{\text {spac }}\right.$-liaHGFSR) were not induced. Squares, $d / t^{+}$; triangles, dltD:: miniTn10; filled symbols, growth; open symbols, $\beta$-galactosidase activity. (b) As in (a), but $\mathrm{P}_{\text {spac }}$-liaHGFSR was induced with $1 \mathrm{mM}$ IPTG.

LL-37, possibly due to elimination of the peptide in the cells. In the presence of IPTG, the overall $\mathrm{P}_{\text {liaI }}$ expression levels were lower (about fourfold reduced) as compared to the expression levels in the absence of IPTG, and the induction was also more transient (Fig. 4a, b). In the wildtype strain (in the absence of IPTG) only a small induction peak was observed (Fig. 4a). These results are similar to and consistent with those obtained for secretion stress.

The pMUTIN2 insertion in the strains of the above experiments probably inactivated the liaI gene. In order to ensure that liaI disruption did not modulate the response patterns of $\mathrm{P}_{\text {liaI }}$ under stress, we also determined the expression levels of the lia genes in the strain pair IH8123 $\left(d l t^{+}\right)$and IH7375 (dltD:: miniTn 10), which do not contain the pMUTIN2 insertion in liaI, by using QRT-PCR. Cells of 
(a)
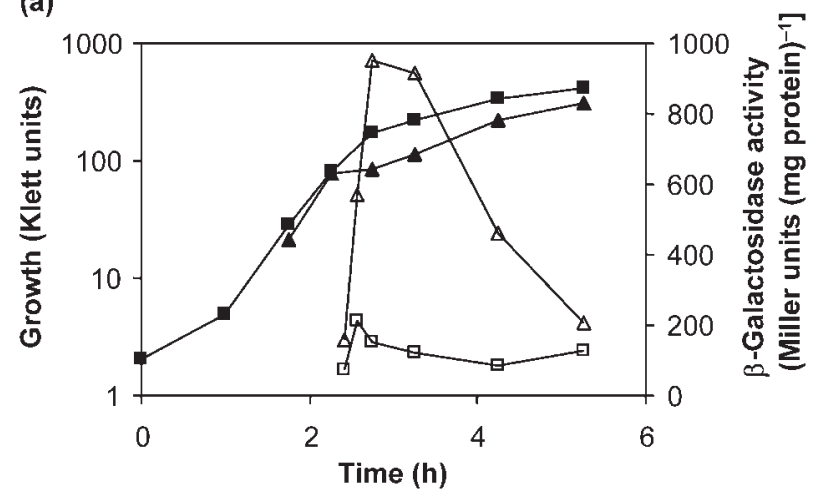

(b)

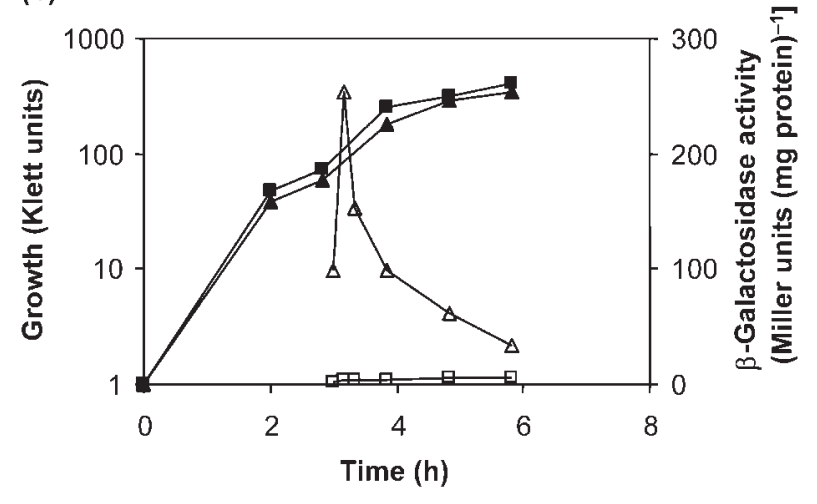

Fig. 4. Induction of $P_{\text {lial }}$ in the $d l t D::$ miniTn 10 mutant by LL-37. (a) Strains IH8220 (dltD : : miniTn 10 lial: : pMUTIN2) and IH8219 $\left(d / t^{+}\right.$lial:: pMUTIN2) were cultivated in $2 \times \mathrm{LB}_{5}$ and treated with LL-37 at a cell density of 60 Klett units for 20 min, followed by determination of $\beta$-galactosidase activities of cell samples taken at the indicated time points during growth. The lia genes downstream of lial ( $\mathrm{P}_{\text {spac }}$-liaHGFSR) were not induced. Squares, $d / t^{+}$; triangles, dlt $D$ : : miniTn 10; filled symbols, growth; open symbols, $\beta$-galactosidase activity. (b) As in (a), but $\mathrm{P}_{\text {spac }}$-liaHGFSR was induced with $1 \mathrm{mM}$ IPTG. these strains were treated with LL-37 for 10 or $20 \mathrm{~min}$, and lia gene expression levels were determined and compared with those in non-treated cells (Table 4). The fold induction values were significantly higher than those obtained with the $\beta$-galactosidase activity measurements due to differences in the sensitivities of the methods. However, consistent with the $\beta$-galactosidase activities ( $\mathrm{P}_{\text {spac }}$ not induced), LL-37 caused a much stronger induction of $\mathrm{P}_{\text {liaI }}$ in the dltD:: miniTn10 mutant than in the wild-type. This stronger induction was evident in the fold induction values of all six lia genes at both time points. The liaI and liaH genes were induced in both strains more strongly than the other lia genes, consistent with the presence of a potential transcription termination loop after liaH (Jordan et al., 2006).

\section{Induction of $P_{\text {lial }}$ by vancomycin or Triton $X-100$ is not enhanced in the dItD: : miniTn10 mutant}

We also studied whether the density of negative charge in the cell wall modulates the response of LiaRS to another cationic-type inducer, the glycopeptide antibiotic vancomycin. Furthermore, we used a non-ionic inducer of LiaRS, the detergent Triton X-100, to find out if the Dlt effect is restricted to cationic inducers such as peptides or if the response to a non-ionic inducer is also affected by the Dlt system. Cells of the $d l t D::$ miniTn 10 mutant and the wildtype strain were treated with vancomycin $\left(2 \mu \mathrm{g} \mathrm{ml}^{-1}\right)$ or $0.005 \%$ Triton X-100 for 10 or 20 min and $\mathrm{P}_{\text {lial }}$ expression was determined using QRT-PCR.

In the wild-type strain, vancomycin enhanced $\mathrm{P}_{\text {liaI }}$ expression (QRT-PCR measurements) hundredsfold as compared to the expression level in non-treated cells (Table 5), consistent with the published results (Mascher et al., 2004) and showing that vancomycin is a strong inducer of the LiaRS TCS. In the dltD:: miniTn 10 mutant, the response to vancomycin was significantly lower (at least sixfold reduced expression of $\mathrm{P}_{\text {liaI }}$, in contrast to the stronger response in

Table 4. Induction of the expression of the lia genes in the dltD: : miniTn10 mutant and the $d l t^{+}$ wild-type strain by LL-37

\begin{tabular}{|c|c|c|c|c|}
\hline \multirow[t]{3}{*}{ Gene } & \multicolumn{4}{|c|}{ Fold induction for strain:* } \\
\hline & \multicolumn{2}{|c|}{ IH8123 $\left(d l t^{+}\right)$} & \multicolumn{2}{|c|}{ IH7375 (dltD: : miniTn 10) } \\
\hline & $10 \mathrm{~min}$ & $20 \mathrm{~min}$ & $10 \mathrm{~min}$ & $20 \mathrm{~min}$ \\
\hline liaI & $19.7(20.6,18.7)$ & $13.4(12.0,14.8)$ & $379.1(532.3,225.9)$ & $318.8(123.0,514.5)$ \\
\hline $\mathrm{liaH}$ & $17.9(14.9,20.8)$ & $15.3(12.9,17.6)$ & $300.4(391.1,209.7)$ & $479.7(140.5,818.9)$ \\
\hline $\operatorname{liaG}$ & $1.7(1.4,2.0)$ & $1.6(1.6,1.6)$ & $29.8(42.9,16.7)$ & $7.3(5.6,9.0)$ \\
\hline liaF & $2.4(2.0,2.7)$ & $1.5(1.8,1.1)$ & $14.9(10.1,19.7)$ & $6.7(4.1,9.2)$ \\
\hline lias & $1.2(1.1,1.3)$ & $1.4(1.6,1.2)$ & $20.9(29.6,12.1)$ & $2.9(2.3,3.4)$ \\
\hline $\operatorname{liaR}$ & $1.3(1.1,1.4)$ & $1.0(1.0,0.9)$ & $8.3(3.7,12.9)$ & $2.0(2.5,1.5)$ \\
\hline
\end{tabular}

*The ratio of the expression level of the gene in LL-37-treated cells to that in untreated cells, as determined by QRT-PCR. The induction ratios are means from two independent experiments. 
the LL-37-treated $d l t D::$ miniTn 10 mutant cells. The fold induction values were similar at both time points.

In the cells treated with Triton X-100, the induction timecourse of $\mathrm{P}_{\text {lial }}$ was such that at the 10 min time point the fold induction was about 60 , and it increased to about 150 at the $20 \mathrm{~min}$ time point (Table 5). There were no significant differences in the induction patterns of the two strains under this stress condition.

\section{DIt modulates the response of the YxdJK TCS to LL-37}

The results of the above experiments suggested that cell wall charge can modulate TCS activity in different ways depending on the TCS and properties of the inducer molecule. YxdJK is a TCS which is activated by LL-37 in a highly specific manner (Pietiäinen et al., 2005). We used YxdJK as the third sensory system to study the Dlt dependence of TCS activation. It was observed that Dlt affects the activity of YxdJK in a similar manner to that of LiaRS, i.e. the activity was enhanced in the dltD::miniTn 10 mutant. There was about a threefold higher induction of the YxdJK-regulated $y x d L$ gene in the dltD::miniTn 10 mutant as compared to the wild-type strain at both the 10 and 20 min time points (Table 5).

\section{Modulating the negative charge of the outer surface of the cell membrane does not affect the activity of TCSs}

In a similar manner to the negative charge of the cell wall, the negative charge of the cell membrane surface could also affect the activity of TCSs. We used mutations that decrease positively charged amines in the membrane and thereby increase the negative charge of the membrane surface. The inactivated components were MprF, which modifies membrane lipids with L-lysine (Peschel et al., 2001; Staubitz \& Peschel, 2002), and Psd, which encodes phosphatidylserine decarboxylase and is involved in the biosynthesis of phosphatidylethanolamine (Cao \& Helmann, 2004; Matsumoto et al., 1998). Both Staphylococcus aureus and B. subtilis synthesize lysylphosphatidylglycerol, and it has been shown with S. aureus that $\mathrm{MprF}$ is responsible for the synthesis (Peschel et al., 2001; Staubitz \& Peschel, 2002). Two pMUTIN2 insertion mutations of the B. subtilis mprF ortholoque, $y f i W:$ :pMUTIN2 and $y f i X:$ :pMUTIN2, were used in this study to characterize the putative role of $\mathrm{MprF}$ in the activation of LiaRS and YxdJK. The psd1::neo mutation (Matsumoto et al., 1998) was used to determine the putative role of Psd in the activation of LiaRS, YxdJK and CssRS.

We first determined the sensitivities of the $y f i X:$ : pMUTIN2 (IH8394) mutant and the wild-type parent ( $m p r F^{+}$, IH8123) to LL-37. LL-37 completely inhibited the growth of the wild-type $B$. subtilis strain in a liquid culture at a concentration of $12 \mu \mathrm{g} \mathrm{ml}^{-1}$, delayed the start of growth at $10 \mu \mathrm{g} \mathrm{ml}^{-1}$ and had no effect on growth at $8 \mu \mathrm{g} \mathrm{ml}^{-1}$. The LL-37 sensitivity of the mutant did not differ from that of the wild-type strain, in contrast to the increased sensitivity of analogous mutants of $S$. aureus to defensins (Peschel et al., 2001). We used a sub-inhibitory concentration of LL-37 (4 or $6 \mu \mathrm{g} \mathrm{ml}^{-1}$ ) and determined the induction of $\mathrm{P}_{\text {liaI }}$ and $\mathrm{P}_{y x d L}$ in the $y f i W::$ pMUTIN2, $y f i X::$ pMUTIN2 and $p s d 1::$ neo mutants and the wild-type

Table 5. Effects of the inactivation of $d l t D, m p r F$ and $p s d$ on $\mathrm{P}_{\text {lial }}$ and $\mathrm{P}_{y x d L}$ expression

\begin{tabular}{|c|c|c|c|c|c|c|}
\hline \multirow[t]{2}{*}{ Strain } & \multirow[t]{2}{*}{ Genotype } & \multirow[t]{2}{*}{ Stress } & \multicolumn{4}{|c|}{ Fold induction ${ }^{\star}$} \\
\hline & & & \multicolumn{2}{|c|}{$\mathbf{P}_{\text {liaI }}$} & \multicolumn{2}{|c|}{$\mathbf{P}_{y x d L}$} \\
\hline IH8123 & wt & LL-37 & $21(17,25)$ & $14(13,14)$ & $55(53,56)$ & $47(35,58)$ \\
\hline IH7375 & $d l t D$ & LL-37 & $417(395,438)$ & $316(122,509)$ & $166(105,226)$ & $169(75,262)$ \\
\hline IH8123 & wt & Triton X-100 & $64(57,71)$ & $135(107,163)$ & ND & $\mathrm{ND}$ \\
\hline IH7375 & $d l t D$ & Triton X-100 & $68(55,80)$ & $188(147,229)$ & $\mathrm{ND}$ & $\mathrm{ND}$ \\
\hline IH8123 & wt & LL-37 & $18(16,20)$ & $12(8,16)$ & $55(53,56)$ & $47(35,58)$ \\
\hline IH7375 & $m p r F(y f i X::$ pMUTIN2) & LL-37 & $33(44,22)$ & $18(20,16)$ & $28(20,36)$ & $44(32,55)$ \\
\hline IH8123 & wt & LL-37 & $1281(192) \dagger$ & $866(351) \dagger$ & $323(181) \dagger$ & $301(37) \dagger$ \\
\hline
\end{tabular}

${ }^{\star}$ The strains were exposed to the indicated stresses, and fold inductions of the liaI and $y x d L$ genes were determined by QRT-PCR after 10 and $20 \mathrm{~min}$ exposure to stress. The fold inductions are means of two or three independent experiments. The fold inductions of the independent experiments (two experiments) or SD (three experiments) are shown in parentheses. ND, Not determined; wt, wild-type.

$\dagger$ In these experiments LL-37 was used at a concentration of $6 \mu \mathrm{g} \mathrm{ml}^{-1}$, whereas in the others the concentration was lower $\left(4 \mu \mathrm{g} \mathrm{ml}{ }^{-1}\right)$, explaining the significant difference in the fold induction values. 
parental strain by QRT-PCR. The mutations had no significant effects on the induction levels of the two promoters (Table 5). Furthermore, psd1::neo did not modulate the activation of $\mathrm{P}_{h t r A}$ by secretion stress [fold inductions: 21.1 (wild-type) versus 19.9 (psd1:: neo)]. These results suggest that the membrane surface charge does not modulate the TCSs.

\section{DISCUSSION}

In this study transcription and proteome analyses were used to demonstrate the role of the Dlt D-alanylation system and the net negative charge of the cell wall in twocomponent signal transduction and gene expression regulation. The transcription measurements and extracellular proteomes of the $d l t D$ mutant and its wild-type parent revealed that the $h \operatorname{tr} A$ and $h \operatorname{tr} B$ genes were expressed at strongly decreased levels in the $d l t D::$ miniTn 10 mutant. This finding is consistent with the stabilization of the PrsA3 protein in the $d l t D:: \operatorname{miniTn} 10$ mutant, since the $\mathrm{HtrA}$ and HtrB quality-control proteases are partially responsible for the degradation of PrsA3 (Hyyryläinen et al., 2001). It was suggested previously that the increased net negative charge of the cell wall in dlt mutants may improve the post-translocational folding of heterologous and mutant proteins that are particularly sensitive to proteolytic degradation (Hyyryläinen et al., 2000). Improved protein folding could decrease stress in the cell envelope and consequently decrease the activity of CssRS and the expression of $h t r A$ and $h t r B$, explaining the findings of the present study and the stabilization of heterologous and mutant proteins in dlt mutants. Alternatively, interactions between misfolded secretory proteins and CssS may be different in the absence and presence of D-alanylated teichoic acids due to changes in electrostatic affinity/ repulsion forces at the cell wall matrix. Such changes could also affect interactions between lipoteichoic acids and CssS, possibly modulating the activity of the TCS. It is evident, however, that the reason for the improved stability of PrsA3 and some heterologous proteins in dlt mutants is probably the decreased levels of the HtrA and HtrB quality control proteases, and consequently decreased degradation. Consistent with the decreased level of HtrA, the level of YqxI (in the extracellular proteome) was also decreased. The secretion and stability of YqxI is probably dependent on HtrA (Antelmann et al., 2003).

The LiaRS system also exhibited a Dlt effect in cells subjected to severe secretion stress or treated with LL-37, but compared to the CssRS system (secretion stress), its direction was the opposite, i.e. a clearly stronger induction of LiaRS, as measured by the expression from $\mathrm{P}_{\text {lial }}$, was observed in the dltD::miniTn10 mutant compared with the wild-type strain $\left(d l t^{+}\right)$. The enhanced induction was observed with both a $\mathrm{P}_{\text {lia }}$-lacZ reporter and by measuring $\mathrm{P}_{\text {liaI }}$ expression with QRT-PCR. The enhanced LiaRS activity may be due to stronger cell envelope stress in the mutant. Most probably, cationic peptides bind to cell envelopes of dlt mutants of Gram-positive bacteria in higher amounts than to those of $d l t^{+}$strains (Peschel et al., 1999). The increased affinity of dlt mutant cell walls to CAMPs subjects the mutant cells to higher stress and increases their sensitivity to CAMPs (Cao \& Helmann, 2004; Kristian et al., 2005; Peschel et al., 1999; Poyart et al., 2003).

The glycopeptide antibiotic vancomycin, also a cationic molecule, is one of the strongest inducers of LiaRS (Mascher et al., 2004), but Dlt modulated the response to vancomycin in a different manner than the response to secretion stress or LL-37. It was found that $\mathrm{P}_{\text {liaI }}$ expression was attenuated in the $d l t D$ mutant as compared to the $d l t^{+}$ strain. In contrast to the responses to these cationic inducers, the LiaRS response to a non-ionic inducer, Triton $\mathrm{X}-100$, was not affected by Dlt.

These results suggest that Gram-positive bacterial cells can modulate two-component signal transduction and gene expression under stress by modulating the density of negative charge in the wall. The expression of the $d l t$ operon is dependent on the extracytoplasmic sigma factor $\sigma^{\mathrm{X}}$ (Cao \& Helmann, 2004), and under some growth conditions probably also on $\sigma^{\mathrm{D}}$ and the Spo0A and $\mathrm{AbrB}$ sporulation proteins (Perego et al., 1995; Cao \& Helmann, 2004). Environmental stress conditions, which activate $\sigma^{\mathrm{X}}$, modulate the net negative charge of the wall by increasing $d l t$ expression and thereby affect the stress response of TCSs. However, the modulation of the stress response may be limited to stress caused by cationic molecules and accumulation of misfolded proteins, and TCSs responding to these stress conditions. Consistent with this conclusion, the YxdJK TCS, which is activated highly specifically by the human cathelicidin LL-37, was also induced in a Dltdependent manner. The induction pattern was similar to that of the LiaRS TCS: stronger induction in the dltD: : miniTn 10 mutant.

The LiaRS and YxdJK TCSs most probably sense a very different type of stress than does CssRS. In addition to our results, such a difference is also suggested by the predicted transmembrane topology of the two-component sensors. The CssS protein has a 137 aa soluble periplasmic region which may have a role in the sensing of misfolded proteins at the membrane-cell wall interface. It is a fairly specific sensor, since membrane-active compounds such as CAMPs or detergents do not activate it. In contrast, LiaS and YxdK do not have a periplasmic domain, suggesting that they are dedicated to sensing intramembrane stress. This may explain why membrane-active CAMPs activate LiaS and YxdK much more strongly than secretion stress. This model may also explain the effect of vancomycin on LiaRS. Since vancomycin strongly activates LiaRS, it probably causes intramembrane stress (e.g. accumulation of cell wall precursors in the membrane), which is alleviated in the absence of D-alanylated teichoic acids.

We also studied whether the degree of lysinylation of the negatively charged phospholipid head groups of the cell 
membrane and the proportion of phosphatidylethanolamine in the membrane lipids could modulate the stress response to LL-37 or protein secretion in a similar manner to the D-alanylation of teichoic and lipoteichoic acids. This was not the case. The induction of LiaRS, YxdJK and CssRS was independent of these factors.

The induction of $\mathrm{P}_{\text {spac }}$-liaHGFSR expression (pMUTIN2 insert at liaI) with IPTG repressed $\mathrm{P}_{\text {liaI }}$ expression. Thorsten Mascher's group (University of Göttingen, Germany) has found that inactivating liaF increases expression from the $\mathrm{P}_{\text {lial }}$ promoter, indicating that LiaF is a negative regulator of $\mathrm{P}_{\text {liaI }}$ (Jordan et al., 2006). LiaF is a putative integral membrane protein and may therefore not repress $\mathrm{P}_{\text {liaI }}$ by directly interacting with the promoter but rather by negatively regulating the activity of LiaRS. LiaH also moderately down-regulates $\mathrm{P}_{\text {liaI }}$ (Jordan et al., 2006). When the lia genes are expressed at low levels (in nonstressed cells), the $\mathrm{P}_{\text {liaI }}$ promoter is capable of responding strongly if the cells are exposed to stress. Under stress conditions, when the lia genes are expressed at high levels, an auto-control mechanism starts to down-regulate $\mathrm{P}_{\text {liaI }}$ expression. The Lia proteins, which are repressors of $\mathrm{P}_{\text {liaI }}$, may have a role in this auto-control, particularly $\mathrm{LiaH}$, since the stoichiometry between LiaH and LiaRS changes dramatically during the activation of the operon.

\section{ACKNOWLEDGEMENTS}

This work was supported by grants from the European Union (Bio4CT96-0097 and QLK3-CT-1999-00413) and the Academy of Finland (53555, 72592, 105997, 107366 and 113846). This work, as part of the European Science Foundation EUROCORES Programme EuroSCOPE is supported by funds from the European Commission's Sixth Framework Programme under contract ERAS-CT2003-980409. We thank Dr Junichi Sekiguchi, Shinshu University, for the $y f i W:: p M U T I N 2$ and $y f i X:: p M U T I N 2$ mutants and Dr Kouji Matsumoto, Saitama University, for the psd1:: neo mutant.

\section{REFERENCES}

Antelmann, H., Tjalsma, H., Voigt, B., Ohlmeier, S., Bron, S., van Dijl, J. M. \& Hecker, M. (2001). A proteomic view on genome-based signal peptide predictions. Genome Res 11, 1484-1502.

Antelmann, H., Yamamoto, H., Sekiguchi, J. \& Hecker, M. (2002). Stabilization of cell wall proteins in Bacillus subtilis: a proteomic approach. Proteomics 2, 591-602.

Antelmann, H., Darmon, E., Noone, D., Veening, J. W., Westers, H., Bron, S., Kuipers, O. P., Devine, K. M., Hecker, M. \& van Dijl, J. M. (2003). The extracellular proteome of Bacillus subtilis under secretion stress conditions. Mol Microbiol 49, 143-156.

Buttner, K., Bernhardt, J., Scharf, C., Schmid, R., Mader, U., Eymann, C., Antelmann, H., Volker, A., Volker, U. \& Hecker, M. (2001). A comprehensive two-dimensional map of cytosolic proteins of Bacillus subtilis. Electrophoresis 22, 2908-2935.

Cao, M. \& Helmann, J. D. (2004). The Bacillus subtilis extracytoplasmic-function $\sigma^{\mathrm{X}}$ factor regulates modification of the cell envelope and resistance to cationic antimicrobial peptides. J Bacteriol 186, $1136-1146$.
Connolly, L., De Las Penas, A., Alba, B. M. \& Gross, C. A. (1997). The response to extracytoplasmic stress in Escherichia coli is controlled by partially overlapping pathways. Genes Dev 11, 2012-2021.

Craynest, M., Jorgensen, S., Sarvas, M. \& Kontinen, V. P. (2003). Enhanced secretion of heterologous cyclodextrin glycosyltransferase by a mutant of Bacillus licheniformis defective in the D-alanylation of teichoic acids. Lett Appl Microbiol 37, 75-80.

Danese, P. N. \& Silhavy, T. J. (1997). The $\sigma^{\mathrm{E}}$ and the Cpx signal transduction systems control the synthesis of periplasmic proteinfolding enzymes in Escherichia coli. Genes Dev 11, 1183-1193.

Darmon, E., Noone, D., Masson, A., Bron, S., Kuipers, O. P., Devine, K. M. \& van Dijl, J. M. (2002). A novel class of heat and secretion stressresponsive genes is controlled by the autoregulated CssRS twocomponent system of Bacillus subtilis. J Bacteriol 184, 5661-5671.

Hastrup, S. \& Jacobs, M. F. (1990). Lethal phenotype conferred by xylose-induced overproduction of Apr-LacZ fusion protein. In Genetics and Biotechnology of Bacilli, pp. 33-41. Edited by M. M. Zukowski, A. T. Ganesan \& J. A. Hoch. San Diego: Academic Press.

Hyyryläinen, H.-L., Vitikainen, M., Thwaite, J., Wu, H., Sarvas, M., Harwood, C., Kontinen, V. \& Spehenson, K. (2000). D-Alanine substitution of teichoic acids as a modulator of protein folding and stability at the cytoplasmic membrane/cell wall interface of Bacillus subtilis. J Biol Chem 275, 26696-26703.

Hyyryläinen, H. L., Bolhuis, A., Darmon, E., Muukkonen, L., Koski, P., Vitikainen, M., Sarvas, M., Pragai, Z., Bron, S. \& other authors (2001). A novel two-component regulatory system in Bacillus subtilis for the survival of severe secretion stress. Mol Microbiol 41, 1159-1172.

Hyyryläinen, H. L., Sarvas, M. \& Kontinen, V. P. (2005). Transcriptome analysis of the secretion stress response of Bacillus subtilis. Appl Microbiol Biotechnol 67, 389-396.

Jordan, S., Junker, A., Helmann, J. D. \& Mascher, T. (2006). Regulation of LiaRS-dependent gene expression in Bacillus subtilis: identification of inhibitor proteins, regulator binding sites, and target genes of a conserved cell envelope stress-sensing two-component system. J Bacteriol 188, 5153-5166.

Kobayashi, K., Ehrlich, S. D., Albertini, A., Amati, G., Andersen, K. K., Arnaud, M., Asai, K., Ashikaga, S., Aymerich, S. \& other authors (2003). Essential Bacillus subtilis genes. Proc Natl Acad Sci U S A 100, 4678-4683.

Kontinen, V. P., Saris, P. \& Sarvas, M. (1991). A gene (prsA) of Bacillus subtilis involved in a novel, late stage of protein export. Mol Microbiol 5, 1273-1283.

Kristian, S. A., Datta, V., Weidenmaier, C., Kansal, R., Fedtke, I., Peschel, A., Gallo, R. L. \& Nizet, V. (2005). D-Alanylation of teichoic acids promotes group A streptococcus antimicrobial peptide resistance, neutrophil survival, and epithelial cell invasion. J Bacteriol 187, 6719-6725.

Leskelä, S., Wahlström, E., Hyyryläinen, H. L., Jacobs, M., Palva, A., Sarvas, M. \& Kontinen, V. P. (1999). Ecs, an ABC transporter of Bacillus subtilis: dual signal transduction functions affecting expression of secreted proteins as well as their secretion. Mol Microbiol 31, 533-543.

Mascher, T., Margulis, N. G., Wang, T., Ye, R. W. \& Helmann, J. D. (2003). Cell wall stress responses in Bacillus subtilis: the regulatory network of the bacitracin stimulon. Mol Microbiol 50, 1591-1604.

Mascher, T., Zimmer, S. L., Smith, T. A. \& Helmann, J. D. (2004). Antibiotic-inducible promoter regulated by the cell envelope stresssensing two-component system LiaRS of Bacillus subtilis. Antimicrob Agents Chemother 48, 2888-2896.

Matsumoto, K., Okada, M., Horikoshi, Y., Matsuzaki, H., Kishi, T., Itaya, M. \& Shibuya, I. (1998). Cloning, sequencing, and disruption of 
the Bacillus subtilis psd gene coding for phosphatidylserine decarboxylase. J Bacteriol 180, 100-106.

Missiakas, D. \& Raina, S. (1997). Protein misfolding in the cell envelope of Escherichia coli: new signaling pathways. Trends Biochem Sci 22, 59-63.

Msadek, T., Kunst, F., Henner, D., Klier, A., Rapoport, G. \& Dedonder, R. (1990). Signal transduction pathway controlling synthesis of a class of degradative enzymes in Bacillus subtilis: expression of the regulatory genes and analysis of mutations in $\operatorname{deg} S$ and $\operatorname{deg} U$. J Bacteriol 172, 824-834.

O'Connell, K. L. \& Stults, J. T. (1997). Identification of mouse liver proteins on two-dimensional electrophoresis gels by matrix-assisted laser desorption/ionization mass spectrometry of in situ enzymatic digests. Electrophoresis 18, 349-359.

Palva, I., Sarvas, M., Lehtovaara, P., Sibakov, M. \& Kääriäinen, L. (1982). Secretion of Escherichia coli $\beta$-lactamase from Bacillus subtilis by the aid of $\alpha$-amylase signal sequence. Proc Natl Acad Sci U S A 79, 5582-5586.

Perego, M., Glaser, P., Minutello, A., Strauch, M. A., Leopold, K. \& Fischer, W. (1995). Incorporation of D-alanine into lipoteichoic acid and wall teichoic acid in Bacillus subtilis. Identification of genes and regulation. J Biol Chem 270, 15598-15606.

Peschel, A., Otto, M., Jack, R. W., Kalbacher, H., Jung, G. \& Götz, F. (1999). Inactivation of the dlt operon in Staphylococcus aureus confers sensitivity to defensins, protegrins and other antimicrobial peptides. $J$ Biol Chem 274, 8405-8410.

Peschel, A., Jack, R. W., Otto, M., Collins, L. V., Staubitz, P., Nicholson, G., Kalbacher, H., Nieuwenhuizen, W. F., Jung, G. \& other authors (2001). Staphylococcus aureus resistance to human defensins and evasion of neutrophil killing via the novel virulence factor MprF is based on modification of membrane lipids with L-lysine. J Exp Med 193, 1067-1076.

Pietiäinen, M., Gardemeister, M., Mecklin, M., Leskelä, S., Sarvas, M. \& Kontinen, V. P. (2005). Cationic antimicrobial peptides elicit a complex stress response in Bacillus subtilis that involves ECF-type sigma factors and two-component signal transduction systems. Microbiology 151, 1577-1592.

Pogliano, J., Lynch, A. S., Belin, D., Lin, E. C. C. \& Beckwith, J. (1997). Regulation of Escherichia coli cell envelope proteins involved in protein folding and degradation by the Cpx two-component system. Genes Dev 11, 1169-1182.
Poyart, C., Pellegrini, E., Marceau, M., Baptista, M., Jaubert, F., Lamy, M. C. \& Trieu-Cuot, P. (2003). Attenuated virulence of Streptococcus agalactiae deficient in D-alanyl-lipoteichoic acid is due to an increased susceptibility to defensins and phagocytic cells. Mol Microbiol 49, 1615-1625.

Raivio, T. L. \& Silhavy, T. J. (1999). The $\sigma^{\mathrm{E}}$ and Cpx regulatory pathways: overlapping but distinct envelope stress responses. Curr Opin Microbiol 2, 159-165.

Sarvas, M., Harwood, C. R., Bron, S. \& van Dijl, J. M. (2004). Posttranslocational folding of secretory proteins in Gram-positive bacteria. Biochim Biophys Acta 1694, 311-327.

Staubitz, P. \& Peschel, A. (2002). MprF-mediated lysinylation of phospholipids in Bacillus subtilis - protection against bacteriocins in terrestrial habitats? Microbiology 148, 3331-3332.

Thwaite, J. E., Baillie, L. W., Carter, N. M., Stephenson, K., Rees, M., Harwood, C. R. \& Emmerson, P. T. (2002). Optimization of the cell wall microenvironment allows increased production of recombinant Bacillus anthracis protective antigen from B. subtilis. Appl Environ Microbiol 68, 227-234.

Tjalsma, H., Antelmann, H., Jongbloed, J. D., Braun, P. G., Darmon, E., Dorenbos, R., Dubois, J. Y., Westers, H., Zanen, G. \& other authors (2004). Proteomics of protein secretion by Bacillus subtilis: separating the 'secrets' of the secretome. Microbiol Mol Biol Rev 68, 207-233.

Vagner, V., Dervyn, E. \& Ehrlich, S. D. (1998). A vector for systematic gene inactivation in Bacillus subtilis. Microbiology 144, 3097-3104.

Vitikainen, M., Pummi, T., Airaksinen, U., Wu, H., Sarvas, M. \& Kontinen, V. P. (2001). Quantitation of the capacity of the secretion apparatus and requirement for PrsA in growth and secretion of $\alpha$ amylase in Bacillus subtilis. J Bacteriol 183, 1881-1890.

Vitikainen, M., Hyyryläinen, H. L., Kivimäki, A., Kontinen, V. P. \& Sarvas, M. (2005). Secretion of heterologous proteins in Bacillus subtilis can be improved by engineering cell components affecting post-translocational protein folding and degradation. J Appl Microbiol 99, 363-375.

Wiegert, T., Homuth, G., Versteeg, S. \& Schumann, W. (2001). Alkaline shock induces the Bacillus subtilis $\sigma^{\mathrm{W}}$ regulon. Mol Microbiol 41, 59-71.

Edited by: T. Msadek. 